4.3. Phân loại chẩn đoán: Trong nghiên cứu của chúng tôi, nhiều khả năng nhiễm nấm là phổ biến nhất với hơn 29/41 bệnh nhân $(70,7 \%)$. Điều này có thể giải thích do đối tượng nghiên cứu của chúng tôi đều đa phần đều là các bệnh nhân COPD và hoặc hen phế quản sử dụng corticoid kéo dài, đái tháo đường, khi có các triệu chứng hô hấp không cải thiện với điều trị thông thường hoặc các triệu chứng dai dẳng, tái phát nhiều lần cần lấy các chất tiết đường hô hấp làm các xét nghiệm tìm nấm.

\section{KẾT LUÂNN}

Qua nghiên cứu trên 41 bệnh nhân nhiễm nấm xâm lấn chúng tôi rút ra một số kết luận sau: Triệu chứng lâm sàng của nhiễm nấm xâm lấn phổi rất đa dạng, nhưng phổ biến là ho đờm $(63,4 \%)$, khó thở $(51,2 \%)$, đau ngực $(31,7 \%)$ và nấm Aspergillus là tác nhân gây bệnh ở đại đa số bệnh nhân (dựa trên xét nghiệm vi sinh $(75,7 \%)$, trong đó Aspergillus fumigatus (65,9\%).

\section{TÀl LIẸU THAM KHẢO}

1. Brown G.D., Denning D.W., Gow N.A.R. và cộng sự. (2012). Hidden Killers: Human Fungal Infections. Sci Transl Med, 4(165), 165rv13-165rv13.
2. Denning D.W. (2015). The ambitious "95-95 by $2025^{\prime \prime}$ roadmap for the diagnosis and management of fungal diseases. Thorax, 70(7), 613-614.

3. Khuyển cáo chẩn đoán và điêuu tri nhiềm nấm xâm lấn, hội hô hấp Việt Nam và Hội Hồi sức cấp cứu và chống độc Việt Nam.

4.Trân Duy Hiến (2014). Đặc điểm lâm sàng, cân lâm sàng và kết quả điêu tri nấm phổi. Luận vằn bác sĩ Y khoa, Đại học Y Hà Nội

5. Philippe B., Ibrahim-Granet O., Prévost M.C. và cộng sự. (2003). Killing of Aspergillus fumigatus by alveolar macrophages is mediated by reactive oxidant intermediates. Infect Immun, 71(6), 3034-3042.

6. Roilides E., Uhlig K., Venzon D. và công sự. (1993). Enhancement of oxidative response and damage caused by human neutrophils to Aspergillus fumigatus hyphae by granulocyte colony-stimulating factor and gamma interferon. Infect Immun, 61(4), 1185-1193.

7. Nguyến Thị Như Quỳnh, Chu Thị Hanh (2018). Đăc điểm lâm sàng, cân lâm sàng và kết quả điểu trị nấm phổi xâm lấn.Luận văn bác sĩ nội trú, Đại học Y Hà Nội.

8. Phạm Khắc Trung, Bùi Văn Lệnh (2010). Nghiên cứu đặc điểm Xquang thường quy và cắt lớp vi tính bênh nhân nấm phổi. Luận văn tốt nghiệp thạc sĩ, Đại học Y Hà Nội.

9. Bùi Xuân Đồng (1984). Nhóm nấm Hypomycettes ở Việt Nam. Nhà xuất bản khoa học kĩ thuât.

\title{
ĐẶC ĐIỂM LÂM SÀNG, ĐIÊ̂N SINH LÝ THẦN KINH CO' TRONG TỔN THƯƠ'NG THẦN KINH HÔNG TO VÀ CÁC NHÁNH DO CHẤN THƯƠNG
}

\section{TÓM TẮT}

Mục đích: Mô tả đặc điểm lâm sàng , điện sinh lý thần kinh cớ, đánh giá tỷ lệ, mức độ tổn thương của bệnh nhân tổn thương thần kinh hông to do chấn thương. Phương pháp nghiên cứu: Nghiên cứu mô tả cắt ngang 62 trường hợp có tổn thương thân kinh hông to và các nhánh do chấn thương đến khám và làm điện sinh lý thần kinh cơ tại bệnh viện Việt Đức từ tháng 7/2020 đến tháng 7/2021. Kết quả: Tổn thương tại khớp gối chiếm 45,2\%, 54,8\% số ca có tổn thương dây thần kinh mác chung, $64,5 \%$ số ca có tổn thương hoàn toàn. Tỷ lệ có hoạt động điện tự phát là 95,2\%. Kết luân: Triêu chứng lâm sàng và điên sinh lý thân kinh cớ trong tổn thương dây thần kinh hông to và các nhánh do tổn thương là rất đa dạng phụ

\footnotetext{
${ }^{1}$ Bệnh viện đa khoa Đức Giang

2Trường Đại hoc Y Hà Nội

${ }^{3}$ Bệnh viện Việt Đức

Chịu trách nhiệm chính: Ngô Văn Duy

Email: drduy238@gmail.com

Ngày nhận bài: 22.6.2021

Ngày phản biên khoa học: 17.8.2021

Ngày duyệt bài: 26.8.2021
}

\author{
Ngô Văn Duy ${ }^{1}$, Nguyễn Anh Tuấn ${ }^{2,3}$
}

thuộc vào vi trí, thời gian và hình thái tổn thương.

Từ khóa: Điện sinh lý thần kinh cơ, thân kinh hông to, chấn thương.

\section{SUMMARY}

\section{INJURY TO THE SCIATIC NERVE AND ITS}

BRANCHES DUE TO TRAUMA: CLINICAL, NEUROMUSCULAR ELECTROPHYSIOLOGY

Objectives: analyzing clinica, neuromuscular electrophysiology, assessment rate, vulnerability of patients with sciatic nerve injury due to trauma. Methods: Cross-sectional descriptive study of 64 case of injury to the sciatic nerve and its branches due to trauma went to Viet Duc hospital for examination and electrophysiology from $7 / 2020$ to $7 / 2021$. Results: Knee injury accounts for $45,2 \%, 54,8 \%$ of case have common peroneal nerve damage, $64,5 \%$ of case have complete injury. The rate of spontaneous electrical activity is $95,2 \%$. Conclusions: The clinical and electrodiagnostic symptoms of the sciatic nerve and its branches due injury are variety, depending on the location, duration and morphology of the lesion.

Keywords: neuromuscular electrophysiology, sciatic nerve, trauma 


\section{I. ĐĂT VẤN ĐỀ}

Chấn thương thần kinh ngoai biên là bênh lý tương đối phổ biến trong thực hành lâm sàng và xảy ra khoảng $3 \%$ trong tất cả các bệnh lý liên quan tới chấn thương. Chấn thương thần kinh ngoại biên ở chi dưới thì tương đối hiếm gặp và chiếm khoảng $20 \%$ tổng số các ca chấn thương của hệ thần kinh nhưng thường có tiên lượng xấu hơn so với những tổn thương thần kinh ngoại biên ở chi trên. Những chấn thương thần kinh ngoại biên ở chi dưới là một trong những nguyên nhân quan trọng gây nên tình trạng tàn tật ở những người tré tuổi từ các mức độ khác nhau như mất cảm giác, mất chức năng vận động, đau và cuối cùng làm suy giảm chức năng của chi ảnh hưởng tới chất lượng cuộc sống. Nghiên cứu toàn diện về đặc điểm lâm sàng, điện sinh lý thần kinh cơ cũng như thiết lập mối liên quan giữa định khu tổn thương, mức độ nặng của tổn thương, tiến triển theo thời gian với khả năng hồi phục của người bệnh sẽ giúp cho việc chẩn đoán sớm, tiên lượng và hướng dẫn lựa chon phương pháp điều trị phù hợp cho người bệnh theo từng giai đoạn tổn thương. Mục tiêu của chúng tôi là mô tả đặc điểm lâm sàng, điện sinh lý thần kinh cơ, tỷ lề, mức đô tổn thương ở bệnh nhân tổn thương thần kinh hông to và các nhánh do chấn thương.

\section{II. ĐốI TƯợNG VÀ PHƯƠNG PHÁP NGHIÊN CỨU}

1. Đối tượng nghiên cứu: Gồm 62 bệnh nhân bị tổn thương dây thần kinh hông to và các nhánh do chấn thương đến khám và làm điện sinh lý thần kinh cơ tại bệnh viện Việt Đức từ $7 / 2020$ đến 7/2021.

\section{Phương pháp nghiên cứu:}

2.1. Phương pháp nghiên cứu: Nghiên cứu mô tả cắt ngang tiến cứu. Trực tiếp thăm khám và ghi chép theo mẫu bệnh án nghiên cứu, khai thác đầy đủ tiền sử, bệnh sử, thăm dò điện sinh lý thần kinh cơ bằng máy Điện sinh lý thẩn kinh Nihon Kohden Model: MEB-9400K.

\subsection{Tiêu chuẩn lựa chọn.}

- Bệnh nhân được chẩn đoán là tổn thương dây thần kinh hông to và các nhánh vào khám và làm điện sinh lý thần kinh cơ tại Bệnh viện Việt Đức

-Bệnh nhân có thời gian bị bệnh it nhất là 3 tuần.

- Bệnh nhân đồng ý tham gia nghiên cứu.

2.3. Tiêu chuẩn loại trừ.

- Bệnh nhân có tiền sử bệnh lý toàn thân nặng (Đái tháo đường, cường giáp, suy giáp, suy tim nặng và các bệnh mạn tính kéo dài khác)

- Bệnh nhân không thu thập đầy đủ dữ liệu về lâm sàng hoặc điện sinh lý thần kinh cơ.
- Bệnh nhân có các rối loạn toàn thân nặng khác không cho phép tiến hành đầy đủ thăm dò điện sinh lý thần kinh cơ (CTSN nặng, hôn mê sau chấn thương, chấn thương hàm mặt...)

3. Xử lý và phân tích số liệu. Các số liệu được nhập và phân tích theo phần mềm thống kê SPSS 22.0. Sử dụng thuật toán Chi - square và so sánh các trung bình.

\section{KẾT QUẢ NGHIÊN CỨU}

1. Đặc điểm chung của nhóm bệnh nhân

1.1. Giới: Có 49 nam (79\%) và 13 nữ (21\%) 1.2. Đô tuôi::

\begin{tabular}{|c|c|c|}
\hline Độ tuổi & Số bệnh nhân & Tỷ lệ \% \\
\hline$<18$ tuối & 12 & 19,4 \\
\hline $18-60$ tuối & 43 & 69,4 \\
\hline$>60$ tuối & 7 & 11,3 \\
\hline
\end{tabular}

1.3. Thời gian tốn thương:

\begin{tabular}{|l|l|l|}
\hline Thời gian tốn thương & Số bệnh nhân Tỷ lệ \%o \\
\hline
\end{tabular}

\begin{tabular}{|c|c|c|}
\hline$<6$ tuân & 10 & 161 \\
\hline $6-12$ tuần & 14 & 22,6 \\
\hline > 12 tuần & 38 & 61,3 \\
\hline
\end{tabular}

1.4. Nguyên nhân chấn thương:

\begin{tabular}{|c|c|c|}
\hline Nguyên nhân & Số bệnh nhân & Tỷ lệ \% \\
\hline Ngã & 13 & 20,9 \\
\hline Tai nạn giao thông & 30 & 48,4 \\
\hline Vềt thương & 12 & 19,4 \\
\hline Nguyên nhân khác & 7 & 11,3 \\
\hline
\end{tabular}

\section{2. Đăcc điểm lâm sàng}

2.1. Bên tổn thương: Bên trái có 45 (72,6\%), bên phải có $17(27,4 \%)$

\subsection{Vi trí tôn thương:}

\begin{tabular}{|c|c|c|}
\hline Vị trí tốn thương & Số bệnh nhân & Tỷ lệ \% \\
\hline Vùng mông & 5 & 8,1 \\
\hline Đùi & 11 & 17,7 \\
\hline Khớp gối & 28 & 45,2 \\
\hline Khoeo chân & 2 & 3,2 \\
\hline Cằng chân & 13 & 21,0 \\
\hline Bàn chân & 3 & 4,8 \\
\hline
\end{tabular}

2.3. Dây thần kinh tốn thương:

\begin{tabular}{|c|c|c|}
\hline $\begin{array}{c}\text { Dây thần kinh } \\
\text { tôn thương }\end{array}$ & $\begin{array}{c}\text { Số bệnh } \\
\text { nhânn }\end{array}$ & $\begin{array}{c}\text { Tỷ lệ } \\
\text { \% }\end{array}$ \\
\hline Dây thần kinh hông to & 20 & 32,3 \\
\hline Dây thần kinh mác chung & 34 & 54,8 \\
\hline Dây thần kinh chày sau & 2 & 3,2 \\
\hline Dây thần kinh mác nông & 1 & 1,6 \\
\hline Dây thần kinh mác sâu & 5 & 8,1 \\
\hline Các dây thần kinh khác & 0 & 0 \\
\hline
\end{tabular}

2.4. Phán xạ gân xương:

\begin{tabular}{|c|c|c|}
\hline Mức độ & Số bệnh nhân & Tỷ lệ \%o \\
\hline Mất & 12 & 19,4 \\
\hline Giảm & 11 & 17,7 \\
\hline Bình thường & 39 & 62,9 \\
\hline
\end{tabular}

2.5. Teo cơ: có 57 bệnh nhân chiếm : 91,9\% 
2.6. Triệu chứng cảm giác:

\begin{tabular}{|c|c|c|}
\hline $\begin{array}{c}\text { Triệu chứnng } \\
\text { cám giác }\end{array}$ & $\begin{array}{c}\text { Số bểnh } \\
\text { nhẩn }\end{array}$ & Tỷ lệ \% \\
\hline Đau & 2 & 3,2 \\
\hline Giảm cảm giác & 26 & 41,9 \\
\hline Mất cảm giác & 26 & 41,9 \\
\hline Bình thường & 8 & 12,9 \\
\hline
\end{tabular}

3. Đặc điểm điên sinh lý.

3.1. Mức độ tổn thương: Tổn thương hoàn toàn có 40 bểnh nhân $(64,5 \%)$, tổn thương không hoàn toàn có 22 bệnh nhân $(35,5 \%)$

3.2. Vận tốc dấn truyền, thời gian tiềm và biên độ vận động của dây thân kinh mác

\begin{tabular}{|c|c|}
\hline & TB \pm SD \\
\hline $\begin{array}{l}\text { Vận tốc dẫn truyền vận động bên } \\
\text { lành }\end{array}$ & $\begin{array}{c}54.5 \pm 3.1 \\
(\mathrm{~m} / \mathrm{s})\end{array}$ \\
\hline $\begin{array}{l}\text { Vận tốc dân truyền vận động bên } \\
\text { bệnh }\end{array}$ & $\begin{array}{c}12.1 \pm 20.3 \\
(\mathrm{~m} / \mathrm{s})\end{array}$ \\
\hline Thời gian tiềm vận động bên lành & $4.6 \pm 0.3(\mathrm{~ms})$ \\
\hline Thời gian tiềm vận động bên bệnh & $5.3 \pm 1.9(\mathrm{~ms})$ \\
\hline Biên độ vận động bên lành & $2.7 \pm 1.2(\mathrm{mV})$ \\
\hline Biên độ vận động bên bệnh & $0.5 \pm 0.9(\mathrm{mV})$ \\
\hline & í gian tiềm và \\
\hline
\end{tabular}

\begin{tabular}{|c|c|}
\hline 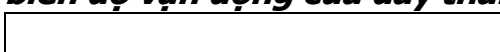 & TB \pm SD \\
\hline $\begin{array}{c}\text { Vận tốc dân truyền vận động } \\
\text { bên lành }\end{array}$ & $52.5 \pm 3.7(\mathrm{~m} / \mathrm{s})$ \\
\hline $\begin{array}{c}\text { Vận tốc dấn truyền vận động } \\
\text { bên bệnh }\end{array}$ & $\begin{array}{c}16.1 \pm 25.3 \\
(\mathrm{~m} / \mathrm{s})\end{array}$ \\
\hline Thời gian tiềm vận động bên lành & $4,1 \pm 0.7(\mathrm{~ms})$ \\
\hline Thời gian tiềm vận động bên bệnh & $4,7 \pm 2.9(\mathrm{~ms})$ \\
\hline Biên độ vận động bên lành & $5.2 \pm 0.8(\mathrm{mV})$ \\
\hline Biên độ vận động bên bệnh & $0.6 \pm 0.9(\mathrm{mV})$ \\
\hline
\end{tabular}
nông

\begin{tabular}{|c|c|}
\hline & $\mathrm{TB} \pm \mathrm{SD}(\mathrm{m} / \mathrm{s})$ \\
\hline $\begin{array}{c}\text { Vận tốc dân truyền cảm giác } \\
\text { bên lành }\end{array}$ & $49.7 \pm 6.6$ \\
\hline $\begin{array}{c}\text { Vận tốc dân truyền cảm giác } \\
\text { bên bệnh }\end{array}$ & $6.9 \pm 20.7$ \\
\hline Thời gian tiềm cảm giác bên lànl & $2.9 \pm 0.6$ \\
\hline Thời gian tiềm cảm giác bên bện & $2,1 \pm 0.5$ \\
\hline Biên độ cảm giác bên lành & $18,1 \pm 5.3$ \\
\hline Biên độ cảm giác bên bệnh & $5.9 \pm 3.5$ \\
\hline $\begin{array}{l}\text { 3.5. Vận tốc dấn truyền v } \\
\text { giác của dây thần kinh gan cl }\end{array}$ & $\begin{array}{l}\text { à biên độ cám } \\
\text { lân ngoài }\end{array}$ \\
\hline & $\mathrm{TB} \pm \mathrm{SD}(\mathrm{m} / \mathrm{s})$ \\
\hline $\begin{array}{c}\text { Vận tốc dân truyền cảm giác } \\
\text { bên lành }\end{array}$ & $41.8 \pm 6.6$ \\
\hline $\begin{array}{c}\text { Vận tốc dân truyền cảm giác } \\
\text { bên bệnh }\end{array}$ & $3.9 \pm 18.7$ \\
\hline Biên độ cảm giác bên lành & $5,8 \pm 2.3$ \\
\hline Biên độ cảm giác bên bệnh & $1,4 \pm 1.5$ \\
\hline
\end{tabular}

3.6. Dấu hiệu điện sinh lý bất thường của dây hông to và các nhánh qua làm điện cơ kim

\begin{tabular}{|c|c|c|}
\hline Điện cơ kim & $\begin{array}{c}\text { Số bệnh } \\
\text { nhân (n) }\end{array}$ & $\begin{array}{c}\text { Tỷ lệ } \\
\mathbf{( \% )}\end{array}$ \\
\hline Hoạt động điện tự phát & 59 & $95,2 \%$ \\
\hline MUAP & 7 & $11,3 \%$ \\
\hline $\begin{array}{c}\text { Hiện tượng kết tập và } \\
\text { giao thoa }\end{array}$ & 38 & $61,3 \%$ \\
\hline
\end{tabular}

\section{BÀN LUÂ̂N}

1. Đặc điểm chung. Nghiên cứu của chúng tôi bao gồm 62 bệnh nhân có tổn thương dây thần kinh hông to và các nhánh do chân thương đến khám và làm điện sinh lý tại bệnh viện Hữu nghị Việt Đức, trong đó tỷ lệ bệnh nhân nam gấp 4 lần bệnh nhân nữ (79\%-21\%) với độ tuổi phổ biến nhất là từ 18 - 60tuổi $(69,4 \%)$, tương đồng với nghiên cứu của Arash Babaei-Ghazani và cộng sự tỷ lệ nam là $83,8 \%$, nữ là $16,2 \%$, độ tuổi: $38,39 \pm 14,42$. [1]

Trong nghiên cứu này, chấn thương chủ yếu là do tai nạn giao thông $(48,4 \%)$ tiếp sau là do ngã do tai nạn lao động $(20,9 \%)$, còn lại đứng hang thứ 3 là do vết thương sắc nhọn $(19,4 \%)$ kết quả này gần tương đông với kết quả nghiên cứu của Arash Babaei-Ghazani và cộng sự tỷ lệ tai nạn giao thông là $55,4 \%$, tai nạn lao động là $27 \%$, vết thương sắc nhọn là $17,6 \%$.[1]

2. Đặc điểm lâm sàng. Trong nghiên cứu của chúng tôi chấn thương thần kinh hông to và các nhánh của nó thường xuất hiện nhiều ở bên trái $(72,6 \%)$, vị trí tổn thương hay gặp nhất là khớp gối $(45,2 \%)$ tiếp sau là cẳng chân $(21 \%)$ và đùi $(17,7 \%)$, tương tự như các báo cáo trước đó trên một quẩn thể lớn bệnh nhân của Igor Immerman và cộng sự thì tỷ lệ gặp chân thương ở khớp gối còn lớn hớn nhiều (75\%) [2].

Trong số các bệnh nhân tham gia nghiên cứu thì tổn thương dây thần kinh mác chung là hay gặp nhất $(54,8 \%)$ sau đó là dây thần kinh hông to $(32,3 \%)$, tổn dây thần kinh chày ít gặp $(3,2 \%)$. Kết quả này gần tương đồng với kết quả nghiên cứu trước đó của Jerzy Gosk và cộng sự tổn thương dây thần kinh mác chung hay gặp nhất $(54 \%)$ và thứ 2 là dây thần kinh hông to $(34,4 \%)[3]$.

Về phản xạ gân xương, tỷ lệ phản xạ gân bình thường gặp nhiêu nhất $(62,9 \%)$ tiếp đó là mất $(19,4 \%)$ và giảm phản xạ gân xương $(17,7 \%)$, trong khi đó tỷ lệ teo cơ gặp rất lớn (91,9\%). Về cảm giác, giảm và mất cảm giác chiếm đa số và có tỷ lệ tương đương $(41,9 \%)$, bênh nhân có cảm giác đau chỉ chiếm $3,2 \%$ gặp ở 2 bệnh nhân có thời gian tổn thương dưới 6 tuần.

3. Đặc điểm điện sinh lý. Chấn thương gây 
tổn thương dây thần kinh chi dưới để lại hậu quả nặng nề, tỷ lệ tổn thương hoàn toàn chiếm $64,5 \%$, tổn thương không hoàn toàn chỉ chiếm $35,5 \%$. Vận tốc dẫn truyền, biên độ của các dây thần kinh bên tổn thương có chỉ số giảm đáng kể so bên lành. Trong khi đó thời gian tiềm của các dây thần kinh bên tổn thương không có sự thay đổi lớn so với bên lành, các kết quả trên tương đồng với kết quả của nghiên cứu trước đây của Paige C. Roy và cộng sự [4].

Hoạt động điện tự phát gặp ở hầu hết các bệnh nhân $(95,2 \%)$ và có $61,3 \%$ các trường hợp là có hiện tượng kết tập và giao thoa. Tuy nhiên chỉ gặp 7\% có hình ảnh đơn vị vận động tại trạng thái co cơ.

\section{KẾT LUÂN}

Triêu chứng lâm sàng và điên sinh lý thần kinh cơ trong tổn thương dây thần kinh hông to và các nhánh do tổn thương là rất đa dạng: bên tổn thương thường gặp là bên trái $(72,6 \%)$, vị trí hay gặp nhất là khớp gối $(45,2 \%)$, thần kinh mác chung là dây thần kinh dễ bị tổn thương nhất ( $54,8 \%)$, tổn thương hoàn toán chiếm đa số $(64,5 \%)$... phụ thuộc vào vị trí, thời gian và hình thái tổn thương.

\section{TÀI LIÊU THAM KHẢO}

1. Babaei-Ghazani A., Eftekharsadat B., Samadirad B. và công sự. (2017). Traumatic lower extremity and lumbosacral peripheral nerve injuries in adults: Electrodiagnostic studies and patients symptoms. J Forensic Leg Med, 52, 89-92.

2. Immerman $I$. và Grossman J.A.I. Lower Extremity Nerve Trauma. Bull Hosp Joint Dis, 10.

3. Gosk J., Rutowski R., và Rabczyñski J. The lower extremity nerve injuries - own experience in surgical treatment. Folia Neuropathol, 5.

4. Roy P.C. (2011). Electrodiagnostic Evaluation of Lower Extremity Neurogenic Problems. Foot Ankle Clin, 16(2), 225-242.

\section{ĐÁNH GIÁ KẾT QUẢ LIỆU PHÁP TIÊM COLLAGEN MD-SHOULDER DƯớI HƯớNG DẪN SIÊU ÂM TRONG ĐIỀU TRI VIÊM GÂN TRÊN GAI}

\section{TÓM TẮT}

Mục tiêu: Đánh giá kết quả điều trị viêm gân trên gai bẳng liệu pháp tiêm Collagen MD-Guna dưới hướng dân siêu âm và đánh giá tác dụng không mong muốn trong 12 tuần theo dõi. Đối tượng và phương pháp nghiên cứu: Nghiên cứu can thiệp lâm sàng, có so sánh với nhóm chứng và so sánh nội nhóm, theo dõi doc trong 12 tuần điều trị trên 61 bênh nhân được chẩn đoán viêm gân trên gai khớp vai và chia thành 2 nhóm. Nhóm 1: gồm 30 bệnh nhân được tiêm Collagen MD-Shoulder $2 \mathrm{ml}$ (1 ống)/lần/tuần vào túi thanh dịch dưới mỏm cùng vai dưới hướng dẫn của siêu âmtrong 5 tuần liên tiếp. Nhóm 2: gồm 31 bệnh nhân được tiêm Depo-Medrol 1 lần duy nhất vào túi thanh dịch dưới mỏm cùng vaidưới hướng dẫn siêu âm. Kết quả: Sau 12 tuần từ thời điểm bắt đâu điều trị: điểm đau VAS trung bình giảm từ 6,8 xuống2,5 điểm (tỷ lệ giảm so với thời điểm trước điều trị là 63,9\%). Điểm đánh giá chức năng vận động khớp vai OSS tăng từ 23,5 $\pm 4,9$ lên 39,7 $\pm 6,9$ điểm (tỷ lệ tăng so với thời điểm trước tiêm là $39,4 \%$ ), cao hơn so với nhóm chứng có ý nghĩa thống kê với $p<0,05$; góc vận động khớp vai tăng từ 122,0 111,3 lên 154,0 $\pm 15,5$ độ (tỷ lệ tăng so với thời điểm trước tiêm là

\section{${ }^{1}$ Bệnh viện $E$ \\ ${ }^{2}$ Trường Đại hoc Y Hà Nội}

Chịu trách nhiệm chính: Nguyễn Vĩnh Ngọc

Email: drngocbm@gmail.com

Ngày nhận bài: 21.6.2021

Ngày phản biên khoa hoc: 16.8.2021

Ngày duyệt bài: 25.8.2021

\section{Đặng Chí Hiếu ${ }^{1}$, Nguyễn Vĩnh Ngọc ${ }^{2}$}

20,6\%). Tỷ lệ đau tăng sau tiêm là 13,3\%. Kết luân: Liệu pháp tiêm Collagen MD-Shoulder dưới hướng dẫn siểu âm trong điều trị viêm gân trên gai có tác dụng giảm đau, cải thiện chức năng vận động và góc vận động sau 12 tuần. Liễu pháp tiêm Collagen MDShoulder dưới hướng dấn siêu âm có hiệu quả giảm đau tương tự, nhưng cải thiện chức năng vận động khớp vai tốt hơn so với liệu pháp tiêm Depo-Medrol ngay từ tuần thứ 5 , kéo dải đến sau 12 tuần điều trị $(\mathrm{p}<0,05)$

Tư khóa: Collagen MD-Shoulder, viêm gân trên gai, tiêm túi thanh dịch dưới mỏm cùng vai dưới hướng dẫn siêu âm. Depo- Medrol.

\section{SUMMARY}

EVALUATE THE RESULTSOF MD-COLLAGEN INJECTION THERAPY UNDER ULTRASOUND GUIDANCEIN THE TREATMENT OF SUPRASPINATUS TENDONITIS

Aims: Evaluate the results of MD-collagen injection therapy in the treatment of supraspinatus tendonitis under ultrasound guidance and evaluate adverse effects of this therapy after 12 weeks of follow-up. Methods: Controlled clinical trial were followed up to 12 weeks in 61 patients with supraspinatus tendonitis, divided into two groups: 30 patients received 5 times in 5 consecutive weeks'sultrasound-guided injection of Collagen MDShoulderinto the subacromial bursa, 31 patientswere given a single ultrasound-guided injection of DepoMedrolinto the subacromial bursa. Results: After 12 weeks of treatment, there was an improvement in VAS, OSS scores, shoulder range of motion in the 